How to cite

Aravind, C.V., Gamboa, R. A., \& Lim, S. C. (2019). Empowered pedagogy: Catching

up with the future. Malaysian Journal of Learning and Instruction, 16(1), 1-22.

\title{
EMPOWERED PEDAGOGY: CATCHING UP WITH THE FUTURE
}

\author{
${ }^{1}$ Chockalingam Aravind Vaithilingam, \\ ${ }^{2}$ Reynato Andal Gamboa \& ${ }^{3}$ Siow Chun Lim \\ ${ }^{1 \& 2}$ School of Engineering, Taylor's University, Malaysia \\ ${ }^{3}$ Electrical and Electronic Engineering, Multimedia University, \\ Malaysia \\ ${ }^{I}$ Corresponding author: chockalingamaravind.vaithilingam@ \\ taylors.edu.my
}

Received: 28 September 2018 Revised : 26 December 2018 Accepted: 10 Mac 2019

\begin{abstract}
Purpose - Recently, a layered and lateral framework that provides opportunities for students to design the pedagogy that creates a broad based, flexible and personalized learning is introduced by the Taylor's University School of Engineering. This approach creates avenue for the students to design their own curriculum within the framework that is developed with inputs from the industry. The framework, the key components, and the tracking of the performance to align the set outcomes through assessment tool is presented.
\end{abstract}

Methodology - My Study Plan (MySP) a macro-enabled software is used to develop a four-year tier model for the students to design the curriculum with the help of a mentor at the start of the programme. Student's learning is monitored on a semester-based learning analytics process implementing the Programme Outcomes (PO) Scorecard. The August 2018 cohort of the Electrical and Electronic Engineering programme is used to pilot this pedagogy.

Findings - Currently the PO measurement is done for the graduating student and focus only on the effectiveness of the programme. The Programme Outcome Assessment Review (POAS) used in this study to monitor the MySP the continual monitoring each semester rather 
towards the end of graduation. Initial simulation of existing PO attainment record of students suggest that this can generate interest towards the learning progress on a semester basis.

Significance - The successful adoption sees an effectiveness in the long run in developing graduates through the continual monitoring of the programme outcomes. The graduating students carry the PO scorecard that complements a second transcript for value addition for their studies. Prospective employers can use the PO scorecard as a metric for initial recruitment purposes, a measure for the soft skills achievements of the applicant.

Keywords: Broad-based education, personalized learning, empowered pedagogy, humanistic, IR 4.0, outcome-based education, programme outcomes.

\section{INTRODUCTION}

\section{Balancing the Curriculum to Meet Future Jobs}

Malaysia's unemployment rate rose from $3.4 \%$ in 2015 to $3.5 \%$ in 2016 , which roughly 15,000 people lost their jobs between the two years span. Is this driven by the economic slowdown or the rise of Industry 4.0? With the Industry 4.0 targeting to generate full rounded graduates, the current industry players and educational watchdog often raise concern, do the students possess the skills set needed in a contemporary workplace? The advancements in Robotics (John, 2011), Virtual Reality (Solotko, 2017), Cloud Computing technology (Griffith, 2015), Big Data Analytics, Artificial Intelligence, the Internet of Things (IBM, 2018) and other technologies are the key drivers in the fourth industrial revolution (IR 4.0). In a futuristic perspective, this is characterized by merging of the technologies and drawing closer lines between the physical, digital and biological aspects for the betterment in life (OECD, 2016).However, the real challenge in the IR 4.0 is not exactly the same as the skills required in the prior revolutionary breakthroughs (Zainal-Abidin, AwangHashim \& Nordin, 2018). The transformation of the realistic IR based characteristics to the human-centered characteristics, including the critical thinking, people management, emotional and inquisitive intelligence, empathically judging, innovative and entrepreneurial, resilience with cognitive flexibility and lifelong 
learning management (Haseeb, 2018). Technology innovations reduce the constraints of students in a classroom environment - instead they collaborate to discuss with peers, be more selfdirected and more independent in their respective way of learning (Jaafar, Awang-Hashim, \& Tengku Ariffin, 2012; Parto, 2013). This imperative drive require more interdisciplinary teaching, research and innovation in universities (Shaari, 2014) making an avenue for high mobility across different sectors possibly in different countries. Convergence of pedagogies across different domains reduces the subject distance between humanities and social science as well as science and technology (OECD, 2016). With the Industrial Revolution 4.0 targeting to generate full rounded graduates, pedagogies often focus on summative assessments.

With the unprecedented change together with a rapid pace towards the IR 4.0 (Katari, 2017), the pedagogical orientation is critical and expected to change over the next decade. Spaced learning (Dalto, 2018), immersive learning (Herrington, Reeves, \& Oliver, 2007), intergroup and empathy based pedagogy is on the rise and the universities around the globe are pulling their curriculum and delivery towards this direction, making the learning happen and prepare the learner towards sustainability on its own (Haseeb, 2018). To continue to succeed as an educational institution in the future, the ability to anticipate change, the agility responding to it and adaptability to respond to our distinctive strengths, both on outstanding teaching quality and student experience. The existing curriculum is largely prescriptive, often limits the choice of learning pertaining to specialized discipline, with little choice to explore the potential of a personalized journey through the curriculum. Both Generation Y and Z are represented with a tag of "Millennials," with growing technology being the primary difference. Generation Y grew-up on personal computers, cell phones, and video game systems, while Generation Z grew with tablets, smartphones, and apps. With the IR 4.0 targeting to generate full rounded graduates, this pedagogy represents the best blend of teaching and learning for the Millenials. A future-ready curriculum needs to re-focus on the jobs of the focus embedding analytics as the way forward, thinking with data for problem-solving which never exists in the prior decade, increasingly losing relevance to finding a job, and moving forward the integration of science and arts balancing out both hemispheres of the brain (Fisk, 2017). So, the basic question is "What kind of curriculum and teaching pedagogy is fitted to address the demand of IR 4.0?" 
The existing curriculum delivery and assessment are based on standardization where the prescribed curriculum never empowered the learning. Recently, in Taylor's University School of Engineering, the course curriculum was revamped with a layered and lateral perspective that could get the opportunity to enhance the students' ability in their area of interests. Within the chosen major, each student designs his own curriculum and modules with the help of a mentor. A four-year tier model is designed by the student to choose a package of modules that makes him technically skewed with expertise or choose allied modules that could support his/her entrepreneurial dream.

\section{Educational Priorities for the Future}

Pedagogies often develop courses that embed skills for employability (Awang-Hashim et al., 2015) or that align directly to career specialization. Most of the pedagogies often help to analyze the progress only at the assessment stage, with a continual quality improvement at the course level and programme level. On the first hand, what is the perfect blend of pedagogy for the Millennials? A common ground for transformation and altering what they wanted to identify their presence globally is the key driver for making the education sustainable. With this, the role of the university is to support the students' needs and essentially as a support to help them to identify routes forward. The major difference between this millennium and the baby boomers (born before 1980) is the way the technology plays in a role in the mindset, with the Millennials having a blended approach towards the learning process while the baby boomers still conservative in the learning process. The key research questions is how the proposed curriculum design aid balance between them to support the employer expectations of looking into the soft skills, allied knowledge (supportive to the domain knowledge), business skills etc., The numerous possibilities that are opening up include spaced learning, immersive learning, flipped learning (reasoning), personalized learning, thus broadening their learning domain with flexible and inquisitive learning. Increasing disruptive innovations in higher education transform products (Yusof et. al., 2016) and/or services that enable providers to offer programmes which are affordable and accessible, often creating a new demand, a new market or a new set of customers (Astin, Vogelgesang, Ikeda, \& Yee, 2000). Increasingly, the learning domains of millennial learners entering higher learning institutions with multiple expectations is summarized in Figure 1. 


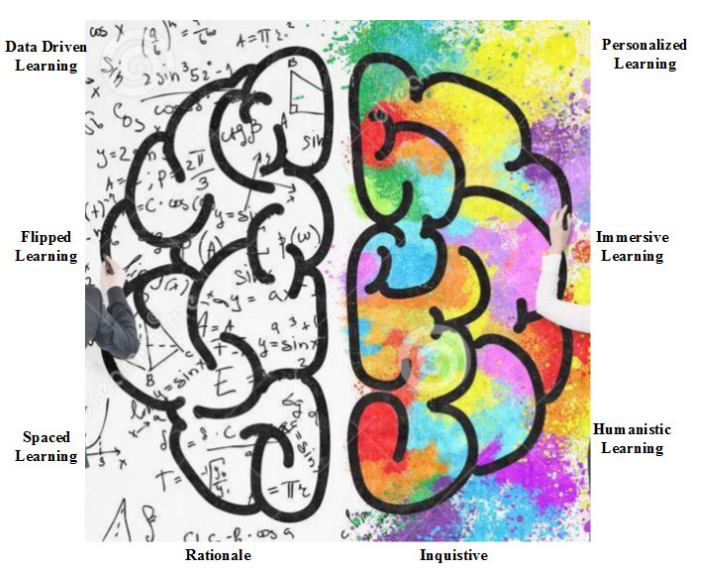

Figure 1. Learning domains of the Millennials.

\section{Future Ready Curriculum Framework}

Taylor's School of Engineering crafted the option and opportunity for the students to have a broad-based, flexible and spaced learning curriculum through personalized learning pedagogy. The idea is to balance out the millennial demand of rationale learning and also the inquisitive learning through the choice and design of curriculum based on the choice of the learners as in Figure 2. In this new framework, the student covers the minimum credit required for the module domain, a mobility programme for their international exposure, bulk credit in the specialized area of expertise the learner wishes to know of, the particular time period for the industry attachment together with the university compulsory core. For example, a student in engineering can choose one of the pathways of the study in his domain area, at the same time he can take up allied course of his interests or on-demand courses (E.g., Blockchain technologies, python programming offered by other schools -up to 5 to 7 modules) making them domain experts together with recent technology know how.

The different analytics within the common framework that would involve the stakeholder (student) as the prime in the design of his own curriculum with the help of the mentor. A macro-enabled tool to aid in the preparation of the study plan is required, where the student can decide the options without compromising the context of 
the course he is registered. The fundamental principle is to integrate the whole study process as a dynamic check and balance for the learner towards fulfilling what is required for the student to be at the end of the university education. From the university perspective, the availability of real-time insights into the performance of learners including students who are at-risk is of significance towards the planning of activities.

Universities are now using data to detect high-risk students and tailor their responses to help prevent dropouts (Thuy-Hang, 2017). A four-model analytics inclusive of an analytic framework are being proposed to help integrate the various analytics used in the choice of the pathways, the curating analytics, the study plan analytics, and the continuous assessment analytics.

Through project-based learning (Al-Atabi \& Tien, 2013), School of Engineering encourages students to explore their passion in their chosen areas of specialization and work on actual projects throughout the duration of their study. The project-based learning pathways where the students pursue their engineering journey with the School of Engineering can be read in Lim, Namasivayam and Vaithilingam, (2018). Three areas of domains are visualized in this new curriculum design giving a broad-based opportunity for the learner, make a flexible way the learning process happens and personalize the learning happening through integrating skills and knowledge across domains. However, the co-curating of the curriculum is bordered by the engineering accreditation council guidelines of minimum credit hours stipulated for being experts in the learner chosen domain including engineering design (Tsang et al., 2001). Table 1 shows the balancing out of the options used for the planning design tool (MySP) as guided by the university core composition structure. The advantage is the curating template is designed with the mentor and the learner during an advisory meeting that would help the learner to lock in his study plan well in advance. Hence, the whole summary of the modules is classified as in Figure 3 with the guidelines of the professional body requirements (EAC Manual, 2017). From the university's perspective, the study plan of the learners across would 
help to mobilize the planning of resources in advance. For instance, less prominent or no takers for a module over time could be replaced with more viable and opportunistic courses that determine the job force at that time or more recent times. This makes the whole system dynamic without deviating much from the learning, and breadth of the module by the learner.

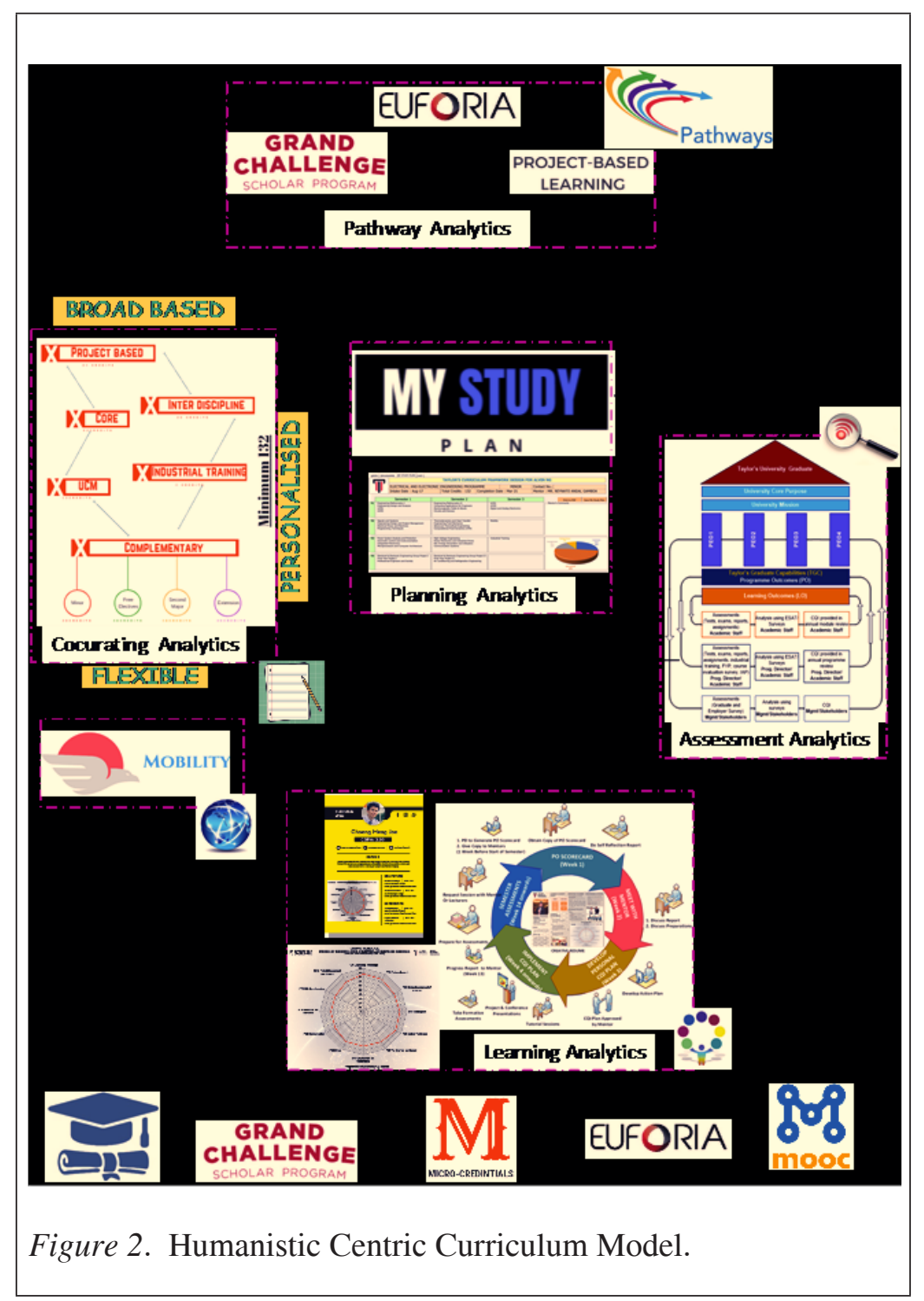




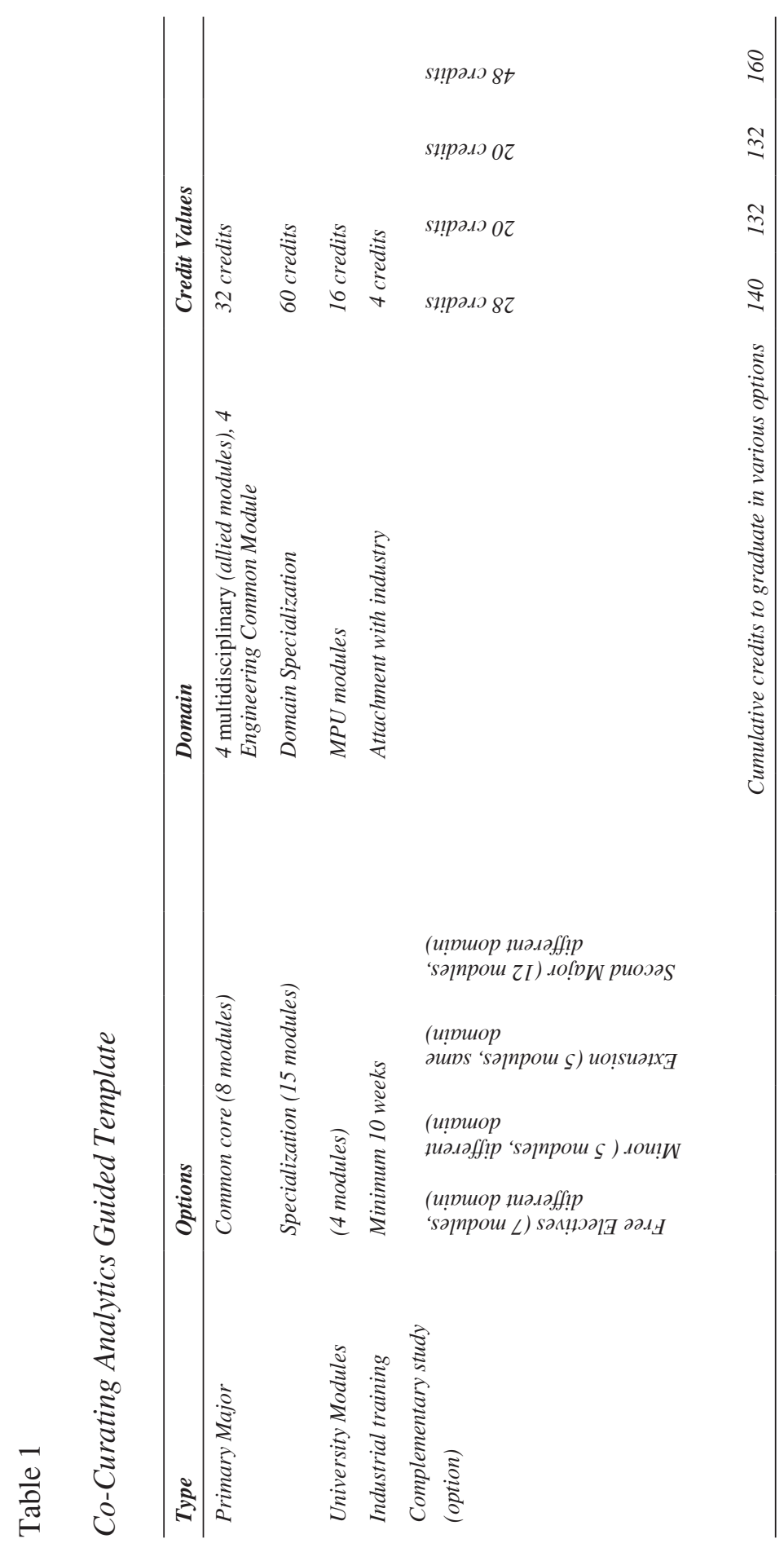




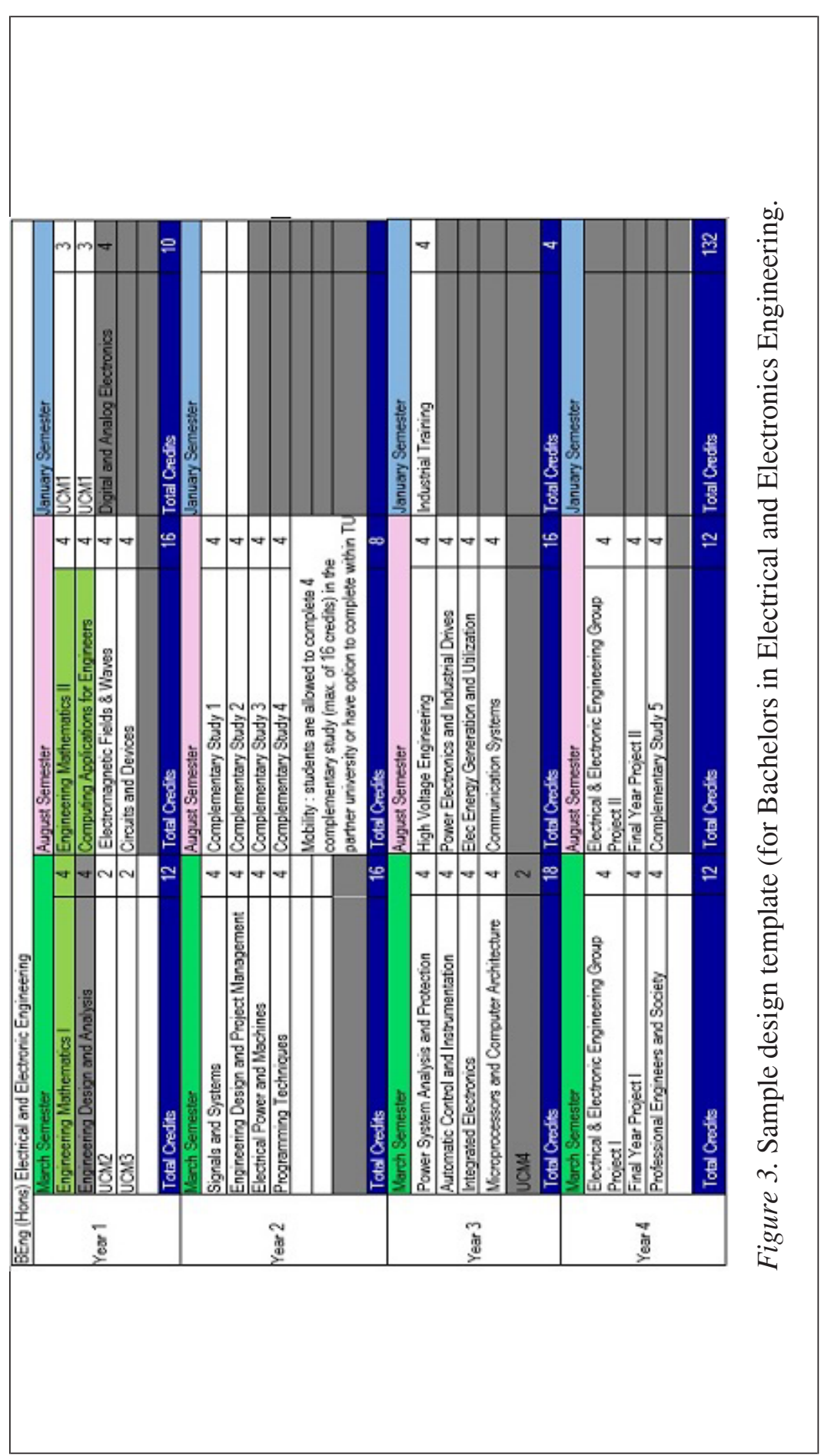




\section{METHODOLOGY}

\section{Constructive Alignment of the Analytics}

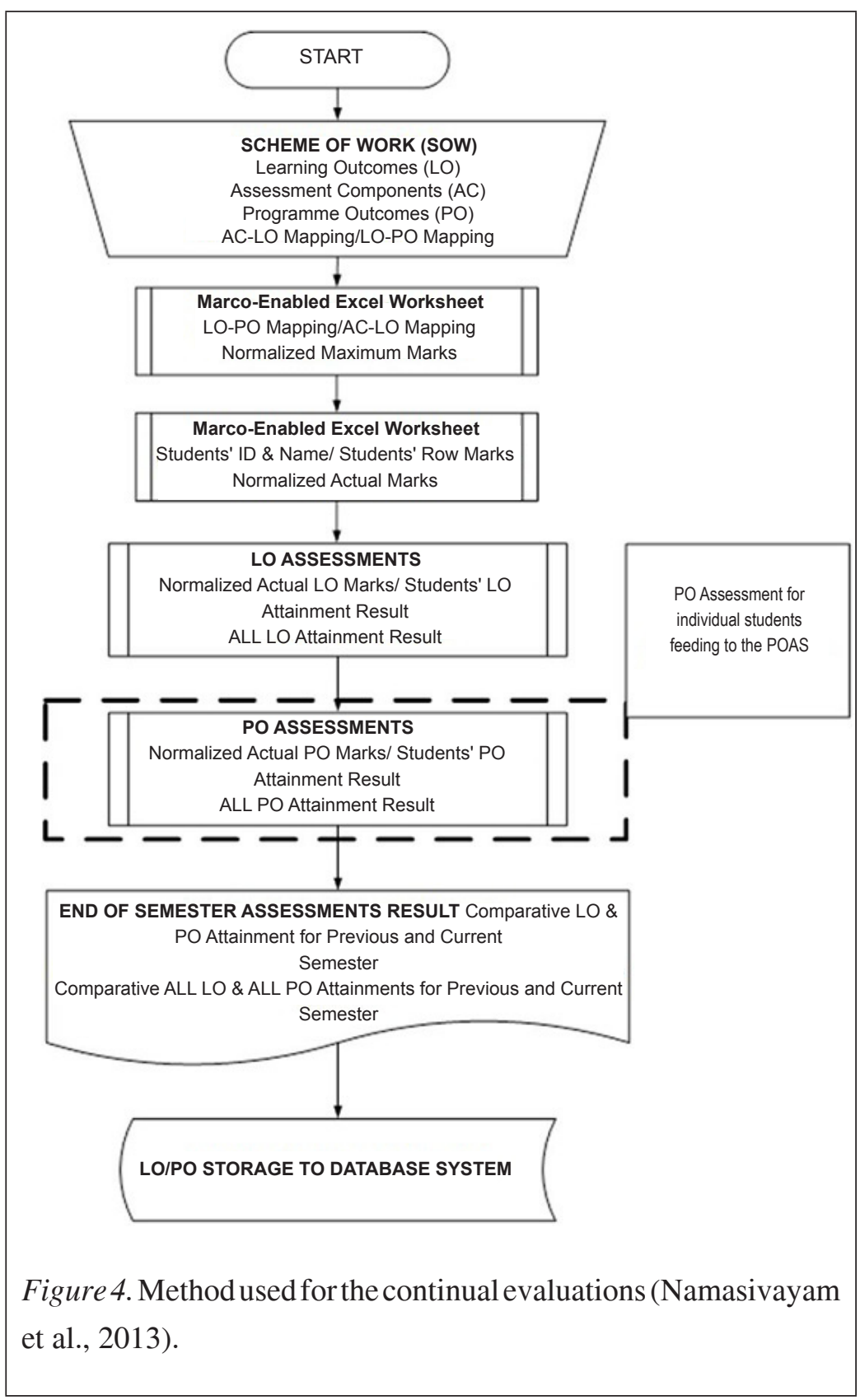


The alignment of the student chosen pathway of his study together with the curriculum plan using the MySP tool is integrated to get the PO attainment report as shown in Figure. 4. The assessment tool developed by Gamboa \& Namasivayam (2013), consists of macroenabled Excel worksheets that focus on the end of semester LO and PO assessments at the module level. This improved model was implemented by the School of Engineering in all of its engineering programmes. The PO feeds information for the development of the POAS scorecard which is important towards the sustainability of the student learning outcome.

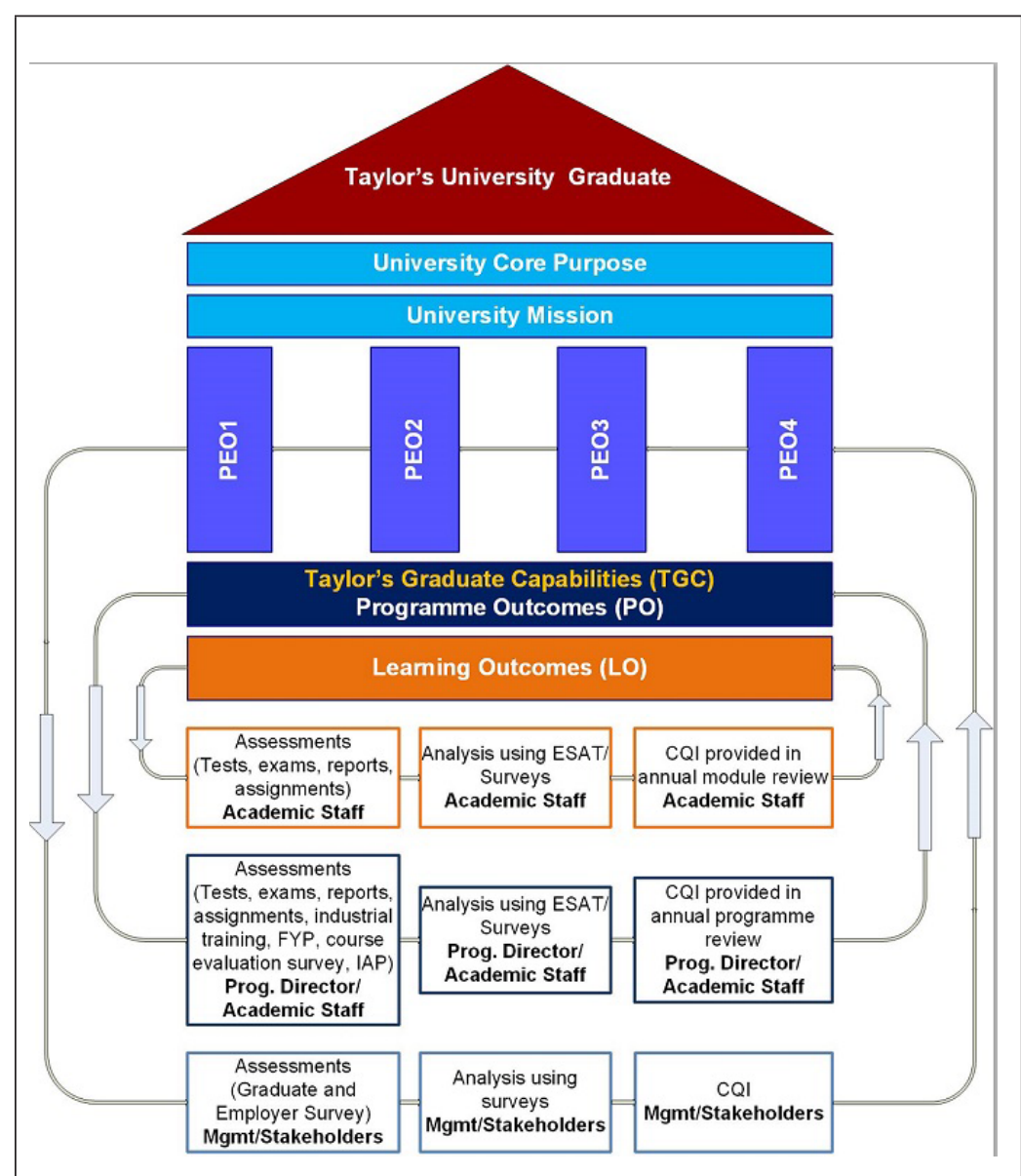

Figure 5. School of Engineering teaching-learning framework (Namasivayam et al., 2013). 
A multiple tier model of teaching and learning for the School of Engineering is developed and is implemented for the continual quality improvement since over 6 years as shown in Figure 5. This is critical for us to conduct the learning outcome (LO) assessment at the module level for immediate continual quality improvement (CQI) action, the PO assessment at the programme level upon graduation of the cohort and the programme educational objectives (PEO) assessment at the school level 3-5 years after graduation to assess the impact to the society. This is a generic template and the measures and action pertaining from the assessment on the impact of outcomes, both at module and programme level is a continually ongoing process with an existing system already in place. A macro enabled tool designed and developed in-house is used to capture the outcomes quantitatively and is used for the analysis and CQI action planning.

The macro-enabled tool is an easy way to visualize the choice of the design process. It also helps to inform the constraints during the design process. This gives ownership to the student to design the way, and to decide what knowledge pyramid they want to acquire before graduation. The design tool has essentially five analytics, including the choice of the pathway of study, co-curating the curriculum through the planning tool along with the students, an assessment analytics together with the learning analytics that make the check and balance of the outcomes, and also give options to redesign the study plan at any point of the four-tier model. With the significance of the education today towards the broad-based knowledge domain, with flexible acquiring of specialization and achieving of personalized goals is the future of the education system. The tool is vital, as it is helping in a major way to balance the assessment learning through the Programme Outcomes (PO) scorecard (Gamboa \& Namasivayam, 2013; Gamboa, Namasivayam, \& Ramesh, 2018) (from the learning analytics) design and modulation of the curriculum (from the planning analytics) the choice and design of streams (pathway and co-curating analytics). This has a major potential in commercialization as individual analytic tool or as a combined tool. Figure 6 shows the My Study Plan (MySP) generated by the macro-enabled tool. The student is given an option to select a complimentary package from either Free Electives, Extension or a Minor package. The student is also given an option where to place his chosen complementary modules in his study plan. The MySP copy 
is unique to the individual student since this is personally chosen by the student with the assistance and supervision of the mentor. The entries in Year 3, semester 2 (in red) are the Minor packages chosen by the student. It consists of 5 modules with 4 credits each. The said MySP will be used to monitor the student's learning progress in a semester basis through the learning analytics described in the previous section.

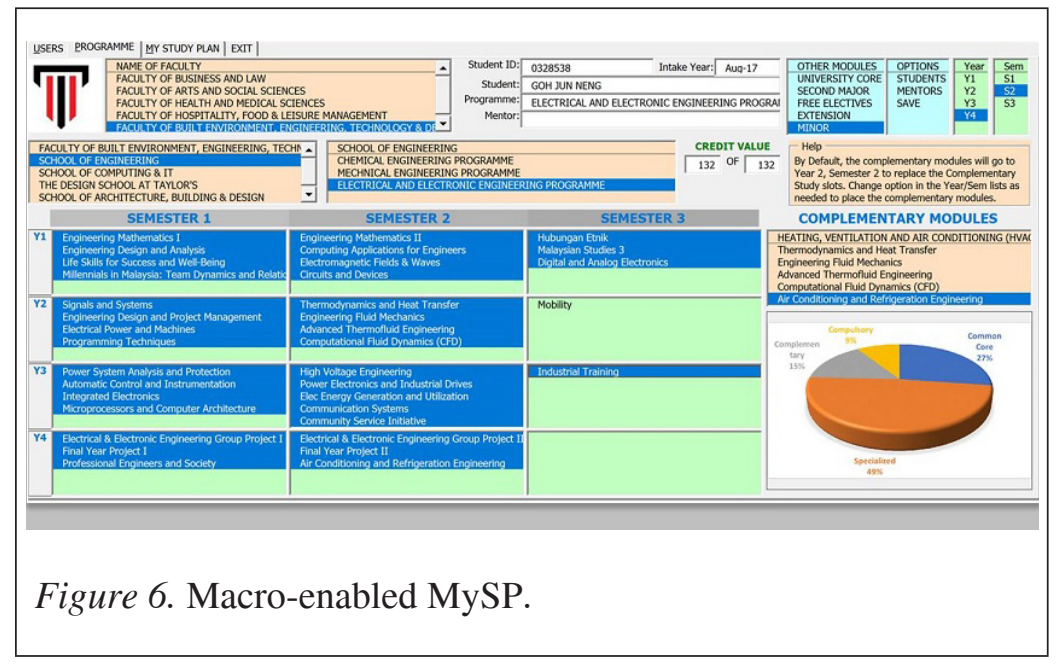

However, the outcomes are cohort or module based and also with some aspects of individual basis is essential for the improvement of the student learning in a semester basis; which got us to develop the learning analytics tool through the PO scorecard. PO scorecard is generated by the End of Semester Assessment Tool (ESAT) which is an exhibition of the student's holistic learning achievement. It is embedded in a Programme Outcome Assessment Review (POAS) process to monitor the student's 14-week semester learning journey (Gamboa \& Namasivayam, 2013). This project is to be piloted for the August 2018 semester. PO Scorecard is a semester-based display of the student's progress in POs achievement. It is a collaborative learning effort of the student, mentor, and the programme CQI and maximizes a student's learning potential. Figure 7 shows the learning analytics process in the 14-week study plan. This systematic approach would help to curate the learning process happening throughout the semester based on the feedback from the assessment component taken from the previous semester. 


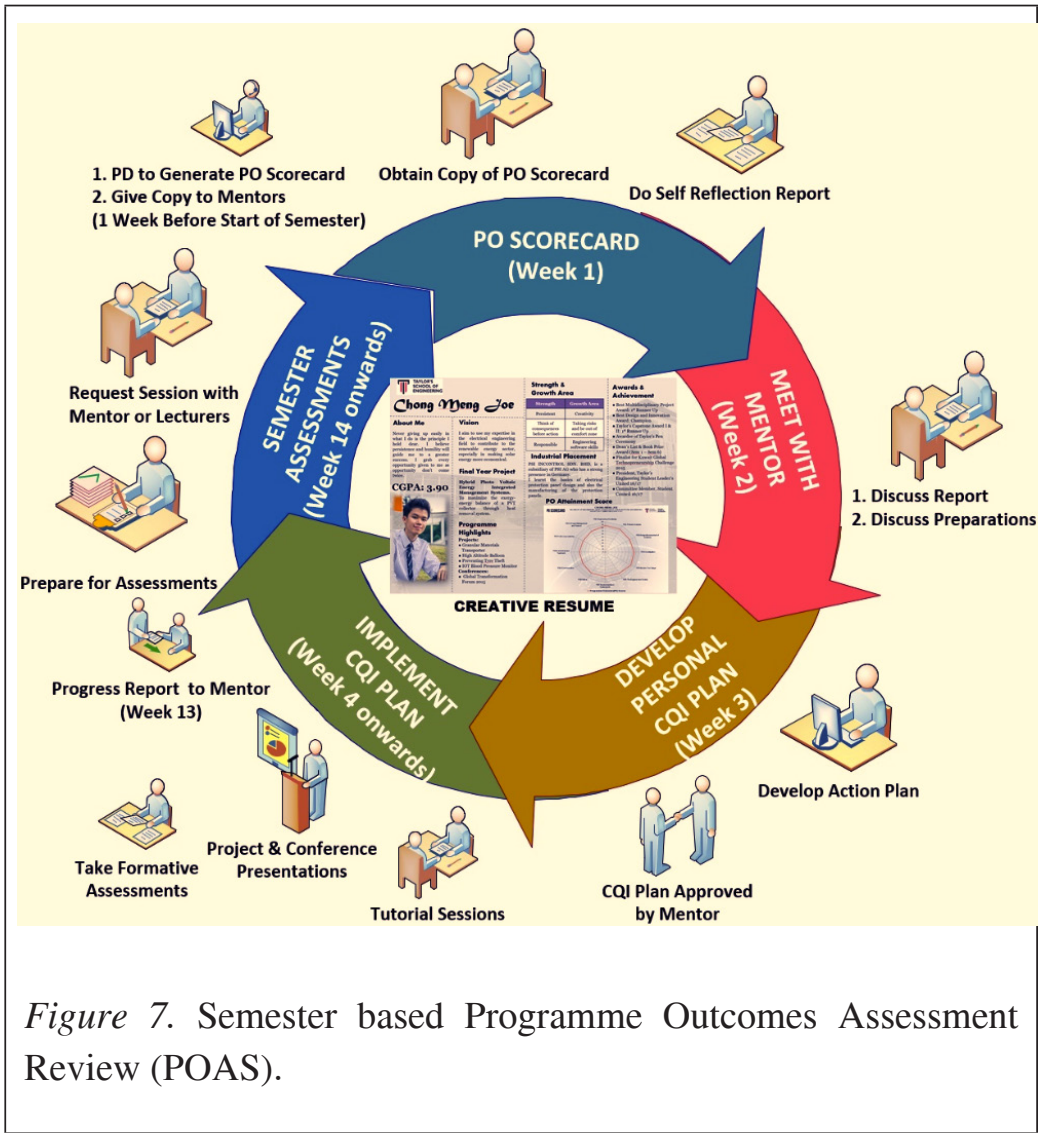

\section{RESULTS AND DISCUSSION}

\section{End of Semester Assessment Tool Analytics}

A PO is said to be attained if the student's PO mark is greater than or equal to the target key performance indicator (KPI). All PO attainments can be computed in a similar manner. The screenshot of the module's PO attainments is shown in Figure 8. This macro enabled tool helps to derive output for the PO attainment of the whole cohort. The tool is also able to generate the learning outcome and PO achievement as seen in Figure 9 of the individual learner, and this helps to track on the continual quality aspects of the system in place. The result can portray the number of students achieving 
their KPIs. The previous semester results were placed side-byside with the present semester results to indicate the effect of CQI implementation. Figure 10 shows the comparison of $\mathrm{PO}$ attainment results.

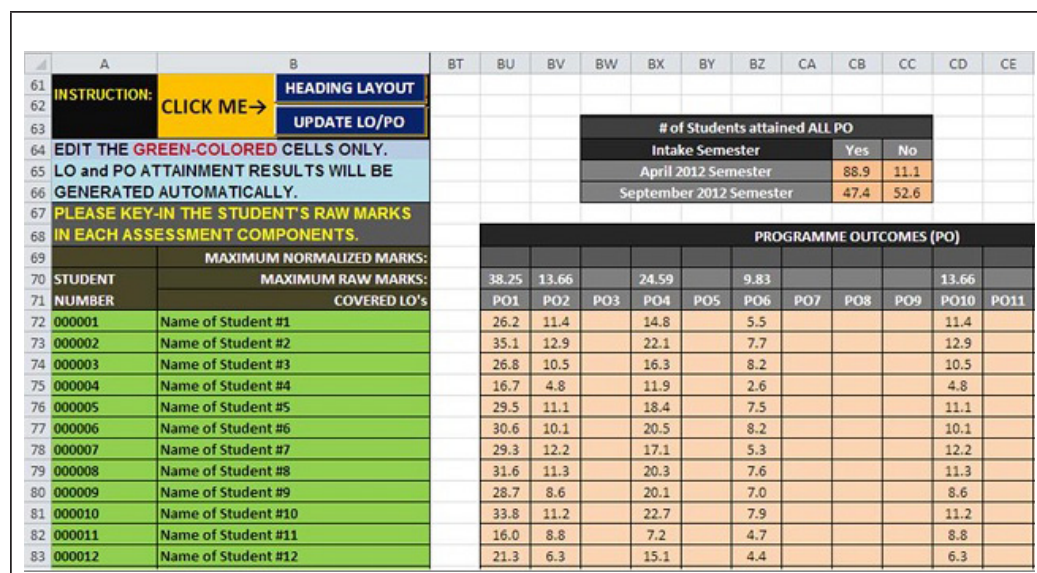

Figure 8. Macro tool for the PO assessment analytics.

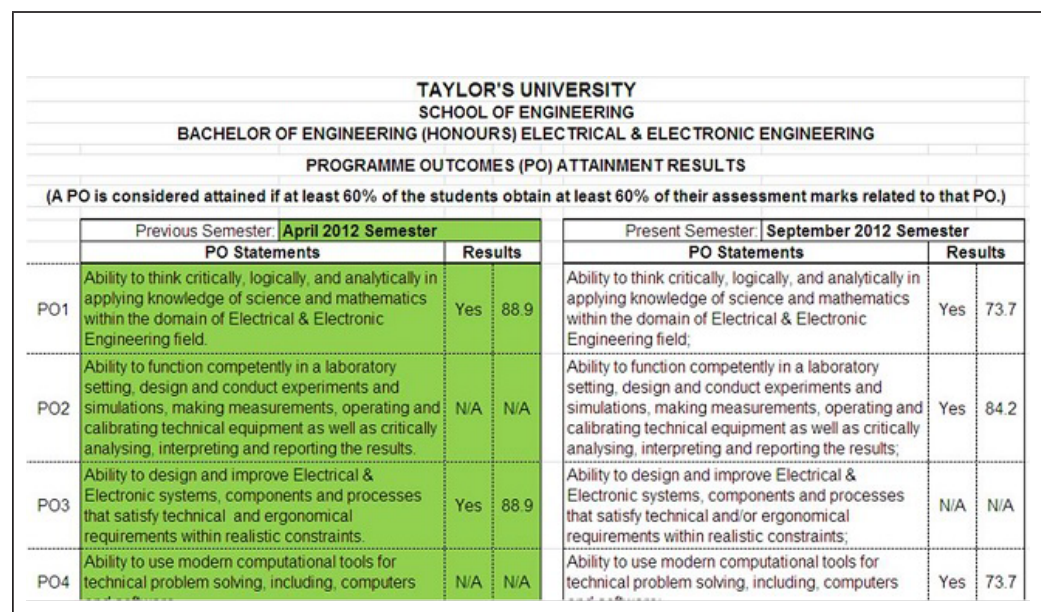

Figure 9. Macro-Enabled Tool for the PO Assessment Analytics. 


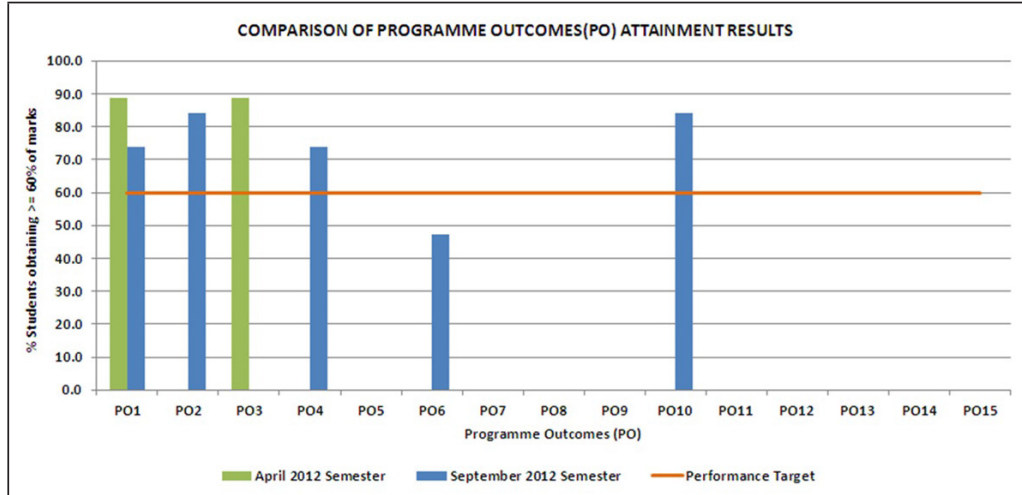

Figure 10. Comparison of PO Attainment Results.

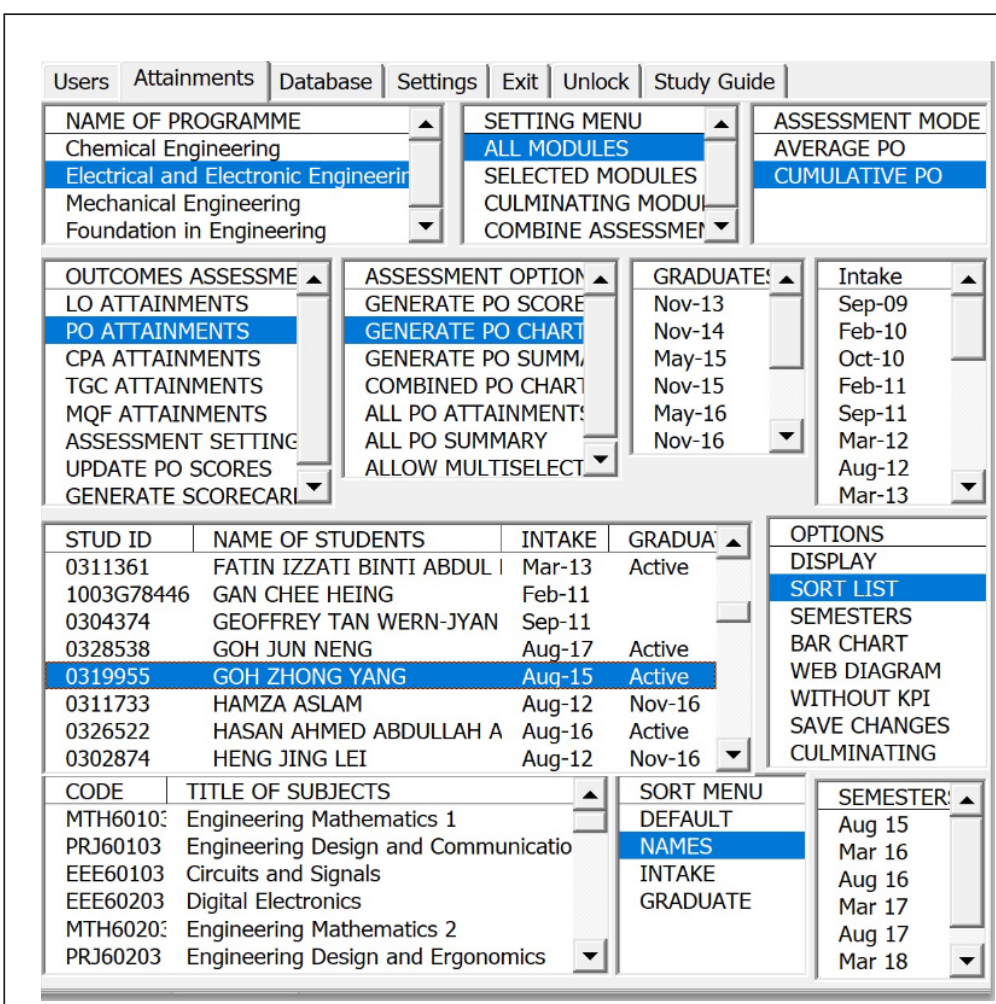

Figure 11. Macro for PO Attainment Results.

In the implementation of POAS, one major component of the process is the student's PO Scorecard generated by ESAT on a semester basis. 
PO Scorecard is used to monitor the student's learning progress on a semester basis. At beginning of the semester, the student is given the copy of his cumulative PO scores. For example, in his semester 1 , there are a few modules which he took and these modules are mapped to a few POs. Figure 11 shows the macro-enabled menu dashboard that helps to generate the scorecard.

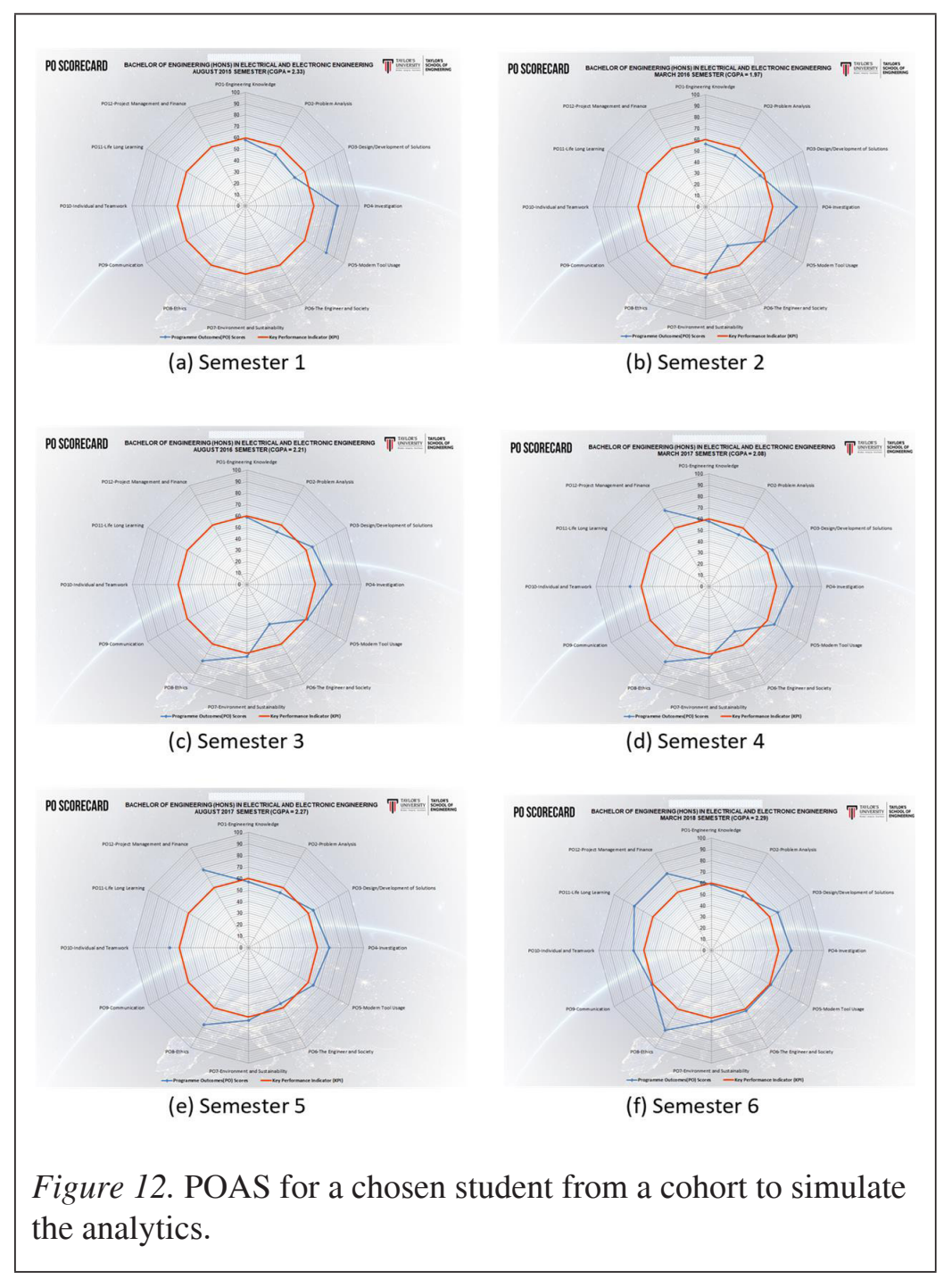

Figure 12 show the screenshots of a student's PO Scorecard from semester 1 to semester 6 respectively. The name of the student was 
concealed to protect his identity. It can be noticed that the student's CGPA is correlated with his PO attainment scores. Gamboa et al. (2018) studied the correlation between the CGPA and PO attainment and found that they are significantly correlated. The KPI is set to 60 which means that a PO is said to achieve KPI if the student's cumulative $\mathrm{PO}$ attainment score is at least 60 . It can also be noticed from Figure 12 that the student's PO1, PO2, and $\mathrm{PO} 3$ attainments are below KPI. These POs are related to cognitive and design skills. Under the semester based POAS process, these POs should be the focus of a CQI action plan for semester 2 if any of the POs are also mapped by the semester 2 modules. The CQI plan should be conceived and developed by the student with the help of the mentor. Monitoring of its implementation starts in week 4 as indicated in the POAS. Before the start of the succeeding semester (semester 2), a new PO scorecard will be generated to check whether the CQI implementation is effective or not in improving the POs. The process in repeated until the last semester of the student under his programme. In the last semester of the student's study, it is expected that all POs should have been achieved. The PO scorecard in the last semester can be used by the student as an attachment to his transcript of record to show how well he achieved the graduateready skills set. The same can be used by the employers in their respective initial recruitment process rather than relying only on the applicant's CGPA.

Newer curriculum design and execution in engineering education targeting to support the IR 4.0 (Zainal-Abidin, Y., 2018 Haseeb, 2018 Dalto, 2018 Herrington, Reeves, \& Oliver, 2007) is need of the hour for educational sustainability primarily due to the disruption caused by the technology in the current generation lives. The effectiveness of such systems in place is evaluated in most of the cases only upon student graduations (Awang-Hashim, R. 2015, Yusof, N., 2016, Yusof, N., 2016). The striking balance on the improvement of the quality of the graduates throughout their study as a check and balance act will help both the learner and the institutions to make the learning more personalized making meaning educational journey. The use of various analytics and embedding tools as such the POAS within the framework add value to the continual quality improvement not only on the curriculum but also on the learner it selves. The exercise is a time consuming process, but in the long run 
once it is integrated into the other analytics and, with the orientation of the big data tools available in the market it is easy to assess the impact of the system and fine tune to the demand of the industry.

\section{CONCLUSIONS}

Both Generation Y and Z are represented with a tag of "Millennials," with growing technology being the primary difference. Generation Y grew-up on personal computers, cell phones, and video game systems, while Generation $\mathrm{Z}$ grew with tablets, smartphones, and apps. With the IR 4.0 targeting to generate full rounded graduates, the pedagogy presented in this paper represents the best blend of teaching and learning for the Millenials. The broad-based, flexible, spaced and personalized learning curriculum design (MySP), the learning process (POAS) and the learning progress monitoring through PO Scorecard can provide a better stimulus to the students in their learning journey and quest for well-rounded skills set upon graduation. The researchers hope that if these features are successfully adopted and implemented by any degree programme, the implementations could lead to a better cohort of graduates ready to meet the industry needs of the future. The final copy of the PO scorecard can be used as a complement to the transcript of record for job application or higher study purposes.

\section{ACKNOWLEDGMENT}

The authors would like to extend gratitude to the eLA -Taylor's University for their help in supporting the disseminations of this project at various forums. This research received no specific grant from any funding agency in the public, commercial, or not-for-profit sectors.

\section{REFERENCES}

Al-Atabi, M., \& Tien, D. T. K. (2013). A blueprint for implementing grand challenge scholar's programme: A case study of Taylor's University. Journal of Engineering Science and Technology, (4), 80-86. 
Astin, A. W., Vogelgesang, L. J., Ikeda, E. K., \& Yee, J. A. (2000). How service learning affects students. Higher Education Research Institute, UCLA, California, 1-7. Retrieved from https://digitalcommons.unomoha.edu

Awang-Hashim, R., Hock-Eam, L., Yatim, B., Tengku-Ariffin, T. F., Zubairi, A. M., Yon, H., \& Osman, O. (2015). Estimating prediction model for early identification of low employability graduates in Malaysia. The Singapore Economic Review, 60(4), 1-22 doi: 10.1142/S0217590815500277

Dalto, J. (2018). Evidence-based training methods and spaced learning (An interview with Dr. Will Thalheimer). Retrieved from https://www.convergencetraining.com/blog/evidencebased-training-methods-and-spaced-learning-an-interviewwith-dr-will-thalheimer

Engineering Accreditation Council Manual (EAC, 2017). Retrieved from http://www.eac.org.my/web/document/Full\%20Version\%20 of\% 20EAC\%20Manual\%202017ed.pdfFisk,P.(2017). Education 4.0 The Future of Learning Will Be Dramatically Different, in School and Throughout Life. Retrieved from https://www.thegeniusworks.com/2017/01/future-educationyoung-everyone-taught-together/

Gamboa, R. A., \& Namasivayam, S. (2013). A Blueprint of Software Enabled Quantitative Measurement of Programme Outcomes: a Case Study for Taylor's University. Journal of Engineering Science and Technology, (Special Issue on Engineering Education), 67-79.

Gamboa, R. A., Namasivayam, S., \& Ramesh, S. (2018). Correlation Study between CGPA and PO Attainment: A Case Study for Taylor's University School of Engineering. In Redesigning Learning for Greater Social Impact (pp. 3-14). Springer, Singapore.

Griffith, E. (2015). What is cloud computing? Retrieved from https:// sea.pcmag.com/networking-communications-software/2919/ what-is-cloud-computing

Haseeb, A. S. (2018). HigherEducation in the EraofIR 4.0. Retrieved from https://www.nst.com.my/education/2018/01/323591/ higher-education-era-ir-40

Herrington, J., Reeves, T. C., \& Oliver, R. (2007). Immersive learning technologies: Realism and online authentic learning. Journal of Computing in Higher Education, 19(1), 80-99.

IBM. (2018). Big Data Analytics. Retrieved from https://www.ibm. com/analytics/hadoop/big-data-analytics 
John, T. S. (2011). Advancements in robotics and its future uses. International Journal of Scientific \& Engineering Research, 2(8), 1-6.

Katari, I. (2017). Industrial Revolution 4.0. Retrieved from https://utminlines.wordpress.com/2017/12/08/industrialrevolution-4-0/

Lim, S. C., Namasivayam, S., \& Vaithilingam, C. A. (2018). The journey of TGCSP with special attention on service learning. In: Tang S., Cheah S. (Eds), Redesigning Learning for Greater Social Impact, Springer, Singapore, 337-344. https://doi. org/10.1007/978-981-10-4223-2_31

Md Jaafar, F., Awang-Hashim, R., \& Tengku Ariffin, T. F. (2012). Malaysian university student learning involvement scale (MUSLIS): Validation of a Student Engagement Model. Malaysian Journal of Learning and Instruction, 9, 15-30.

Namasivayam, S., Al-Atabi, M., Chong, C. H., Choong, F., Hosseini, M. F., Gamboa, R. A., \& Sivanesan, S. (2013). A blueprint for executing continual quality improvement in an engineering undergraduate programme. Journal of Engineering Science and Technology, (Special Issue on Engineering Education), 31-38.

OECD (Ed.). (2016). Innovating education and educating for innovation: The power of digital technologies and skills. Paris: OECD Publishing. Retrieved from http://www.oecd. org/education/ceri/GEIS2016-Background-document.pdf

Parto, S. (2013). The impact of disruptive technology-based innovations in higher education. Retrieved from https:// evolllution.com/opinions/impact-disruptive-technologybased-innovations-higher-education/

Solotko, S. (2017). Virtual reality is the next training ground for artificial intelligence. Retrieved from https://www.forbes. $\mathrm{com} / \mathrm{sites} /$ tiriasresearch/2017/10/11/virtual-reality-is-thenext-training-ground-for-artificial-intelligence/

Shaari, A. S., Mohd-Yusoff, N., Mohd Ghazali, I., Osman, R., Mohd Dzahir, N. F. (2014). The relationship between lecturers' teaching style and students' academic engagement. Procedia - Social and Behavioral Sciences, 118, 10-20.

Thuy-Hang, B. T., Kaur, A., \& Busthami-Nur, A.H. (2017). A selfdetermination theory based motivational model on intentions to drop-out of vocational schools in Vietnam. Malaysian Journal of Learning \& Instruction, 14(1), 1-21. 
Tsang, E., Haneghan, J. V., Johnson, B., Newman, E. J., \& Eck, S. V. (2001). A report on service-learning and engineering design: Service-Learning's effect on students learning engineering design in introduction to mechanical engineering. International Journal of Engineering Education, 17(1), 3039.

Yusof, N., Awang-Hashim, R., \& Kok-Kian, C., (2016). Investigating learning space for research workspaces in higher education in Malaysia. Malaysian Journal of Learning \& Instruction, 13(2), 201-226.

Zainal-Abidin, Y., Awang-Hashim, R., \& Nordin, H (2018). the life story of a resilient underprivileged youth: Motivation to learn soft skills. Malaysian Journal of Learning \& Instruction, 15(1), 57-81 